\title{
De amores y laberintos: utilización del mito cretense en Lope de Vega, Calderón y sor Juana

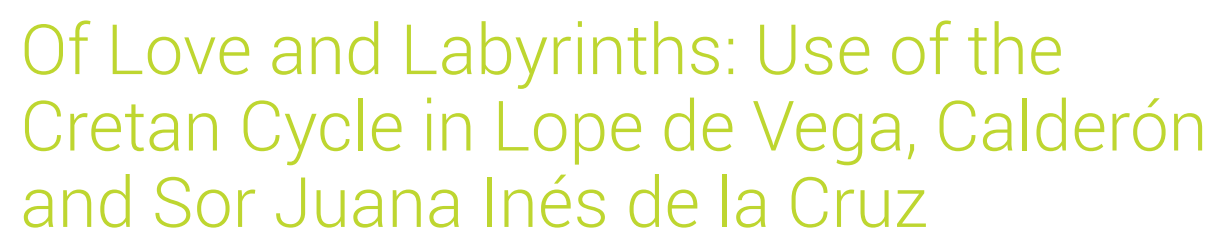

\section{Yadira Munguía}

Universidad Panamericana

Departamento de Humanidades

MÉXICO

Imunguia@up.edu.mx

[Hipogrifo, (issn: 2328-1308), 7.2, 2019, pp. 497-510]

Recibido: 16-06-2018 / Aceptado: 25-09-2018

DOI: http://dx.doi.org/10.13035/H.2019.07.02.39

Resumen. En este trabajo se hizo un análisis entre tres obras: El laberinto de Creta (1621) de Lope de Vega, Amor es más laberinto (1689) de sor Juana Inés de la Cruz y Los tres mayores prodigios (1641) de Calderón de la Barca, haciendo un estudio comparativo sobre las fuentes y su utilización en las comedias mencionadas. Se puso especial atención al desarrollo de los personajes femeninos de las tres comedias, y se observó la influencia de Lope en los otros dos dramaturgos y la primacía argumental de los personajes de Ariadna y Fedra.

Palabras clave. El laberinto de Creta; Amor es más laberinto; sor Juana; Lope de Vega; Calderón de la Barca.

Abstract. In this research an analysis was made between three literary works: The Labyrinth of Crete by Lope de Vega (1621), Love the Greatest Labyrinth by Sor Juana Inés de la Cruz (1689) and The Three Greatest Wonders by Calderón de la Barca (1641) by a comparative study on the sources and their use in the mentioned comedies. Special attention was paid to the development of the female characters of the three comedies, and the influence of Lope de Vega prevailed over the other two playwrights as well as the argumentative primacy of the characters of Ariadne and Phaedra. 
Keywords. The Labyrinth of Crete; Love the greatest labyrinth; Sor Juana; Lope de Vega; Calderón de la Barca.

\section{INTRODUCCIÓN}

Los autores literarios áureos y por consiguiente los novohispanos, repensaron y utilizaron buena parte de las obras de los clásicos grecolatinos para sus propias creaciones, evidencia del espíritu renacentista que existía en el ambiente intelectual del Siglo de Oro ${ }^{1}$, pero también ese recurso fungió como una forma fina de granjearse a la corte e incluso externar ideas de diversa índole que de otra manera no hubiera sido posible trasmitir. Entre los acercamientos a los clásicos nos encontramos sobre todo la utilización de la mitología como tema y ejemplificación; una muestra la tenemos en el teatro, donde encontramos comedias en las que el mito clásico constituye el eje medular. En este trabajo destacamos el ciclo cretense ${ }^{2}$ en tres obras: El laberinto de Creta $^{3}$ de Lope de Vega, Amor es más laberinto ${ }^{4}$ de sor Juana Inés de la Cruz y Los tres mayores prodigios ${ }^{5}$ de Calderón de la Barca, haciendo un estudio comparativo sobre las fuentes y su utilización en las comedias mencionadas.

El teatro para la nobleza, donde situamos el mito, inicia desde tiempos medievales, «pero el auge del teatro de corte se sitúa en el siglo XVII y tendrá en Calderón su máximo exponente», como menciona Ignacio Arellano ${ }^{6}$. Las comedias mitológicas en el Siglo de Oro no son muy abundantes ${ }^{7}$, pero tienen una suma importancia en varios niveles, desde el literario hasta el político. El interés por estas obras se centra sobre todo en los últimos años, en que se ha acrecentado el rescate y los comenta-

1. Dice Mónica Paladino que «el éxito de la comedia mitológica es producto del gusto de la época y esto se combina con el ya generalizado (y reclamado por el público) tratamiento del tema amoroso» (2018, p. 367).

2. Con «ciclo cretense» nos referimos a los mitos que van del rapto de Europa al destino de Dédalo y Minos. Esta serie de mitos han sido muy recurridos en la literatura por sus diversas implicaciones simbólicas. Podemos mencionar además de los clásicos, a Dante, Boccaccio, Shakespeare, Racine, Voltaire, Nietzsche, Rimbaud, entre otros, que retoman y resignifican el mito. En el teatro español uno de los primeros es Lope, le siguen Tirso, Calderón, sor Juana y varios más. Ver Martínez García, 1999.

3. Nos dice Menéndez y Pelayo: «Tragicomedia anterior a 1618; puesto que está citada en la segunda lista de El peregrino. Publicada en 1621, en la Parte decimosexta de las comedias de Lope» (1921, p. 188). Recordemos que El peregrino son listas hechas por el mismo Lope para hacer nota de sus obras, para información al respecto ver Villarejo, 1963.

4. Comedia dedicada al virrey Gaspar de Silva, Conde de Galve en 1689 y representada el 11 de enero de ese año. Publicado en el Segundo volumen de las obras de Sor Juana Inés de la Cruz (1692).

5. Indica Menéndez y Pelayo: «fue representada delante de Felipe IV la noche de San Juan de 1636 en el patio del Palacio Real del Retiro» (1921, p. 193). La comedia en tres partes: Hércules, Teseo y Jasón, fue representada en espacios diferentes.

6. Arellano, 2001, p. 9.

7. Para un repaso del estado de la cuestión de las comedias mitológicas de Lope ver Ávila, 2017, quien hace un interesante repaso de los estudios generales y sobre todo recientes, tanto del concepto de teatro mitológico como de los tópicos y reflexiones acerca de las comedias. 
rios acerca de las fiestas mitológicas. Debemos entender, como propone Sebastián Neumeister, que:

La mitología clásica permite a Calderón y a sus contemporáneos encontrar la forma de integrarse en aquella moda de fiestas cortesanas que, desde los trionfi de las ciudades-estado italianas, había contagiado a toda Europa, pero, al mismo tiempo, llevar a cabo la intensión de crear un significado por encima del tiempo, hecho de importancia primordial para la corte ${ }^{8}$.

Las comedias mitológicas de nuestros tres autores se insertan en una temática y forma de teatro pensada para la corte y alejada de las fórmulas tradicionales escritas para los corrales, por lo tanto son elitistas. Las tramas, basadas en la mitología grecolatina, suponían una cultura general previa que se esperaba tuviera la nobleza, a diferencia de las obras más accesibles a un público general y con menos preparación, como la que asistía a los corrales. Los personajes mitológicos no son tomados en toda su esfera tradicional, «suelen ser humanos y seres sobrenaturales, pero presentes en las narraciones grecolatinas, sin valor historiográfico» ${ }^{9}$, se toman algunas de sus características, pero sin un peso histórico purista.

Los dramaturgos podían también explayarse en un lenguaje y situaciones más elaboradas, incluso la separación de situaciones y caracteres de los seres mitológicos, daban la oportunidad de «echar también una Ojeda sobre el mundo de los dioses, es decir sobre la dimensión metafísica de nuestra existencia», como menciona Neumeister ${ }^{10}$. Lo anterior es notorio en las tres obras que son motivo de este trabajo, las tres están pensadas para un público cortés, no solo en su escritura sino también en su representación, recordemos que las comedias mitológicas se distinguieron por ser verdaderos festejos barrocos con enormes despliegues escenográficos ${ }^{11}$, de vestuario y tramoya ${ }^{12}$.

Otra característica del teatro mitológico es su separación de los mitos originales, modificando la historia para ajustarla a los cánones estéticos de la comedia nueva, y tomando como base argumental las interpretaciones de los clásicos y no las fuentes directas. La recreación que hacen, Lope, Calderón y sor Juana, limitan los episodios del mito a los puntos que sirven para la trama de su comedia, pasando por alto otros indispensables en el relato original.

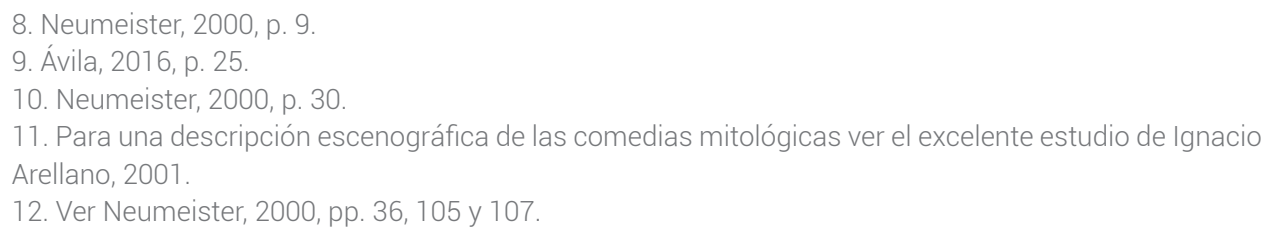




\section{Argumento en el mito CLÁsico}

El mito fundacional alrededor de Creta nos deja ver la relación entre Oriente y Occidente ${ }^{13}$, así como la cercanía entre lo legendario y la realidad histórica, que nos demuestra la significación del ciclo como una percepción de la Grecia Clásica hacia su pasado remoto, que aunque lejano y extraño reconocían como el origen de sí mismos, un origen no entendido del todo y por tanto extrapolado y vuelto a significar a partir de su mitología ${ }^{14}$. Son varios los autores clásicos que retoman el mito cretense, dándonos a conocer distintos aspectos y momentos, entre ellos podemos mencionar a Apolodoro ${ }^{15}$, Heródoto ${ }^{16}$, Pausanias ${ }^{17}$, Higino ${ }^{18}$, Virgilio ${ }^{19}$, Plutarco ${ }^{20}$, Diodoro ${ }^{21}$, Cátulo ${ }^{22}$, Séneca ${ }^{23}$ y como punto esencial para nuestro trabajo, Ovidio, fuente de conocimiento e inspiración para los autores áureos, sobre todo con Las metamorfosis ${ }^{24}$ y las Heroidas ${ }^{25}$.

Podríamos resumir el ciclo cretense en el siguiente argumento, extractado de los autores clásicos arriba mencionados: Zeus, enamorado de la princesa fenicia Europa decide transfigurarse en un toro blanco para llamar su atención. Saliendo de las aguas se dejó acariciar por la princesa y sus acompañantes. Europa sube al lomo del toro y este huye mar adentro. Zeus la lleva a Creta, donde había pasado su infancia. Europa y Zeus tienen tres hijos: Minos, Sarpedón y Radamantis, quienes crecen como hijos de Asterión, rey de Creta, con quien se casó Europa después del abandono de Zeus ${ }^{26}$. Una vez muerto el rey, se inició una disputa por el trono de Creta, enfrentamiento del que salió vencedor Minos gracias al apoyo de Poseidón, quien hace salir del mar un enorme toro blanco, con el cual significaba el favor sobre Minos. A cambio pidió que le sacrificara el animal, petición que Minos no cumplió. Como venganza, el dios del mar, hizo que Pasifae, esposa de Minos e hija

13. Este tema lo podemos ver señalado en el estudio que hace Menéndez y Pelayo sobre las comedias mitológicas de Lope, en el que nos muestra un paralelismo entre los mitos griegos y egipcios. Ver Menéndez y Pelayo, 1921, p. 189.

14. Esto también sucede en la literatura áurea, como menciona Fréderic Serralta: «a partir de los mismos significantes míticos se puede apreciar una gran variedad de significados» (2017, p. 424).

15. Apolodoro, Biblioteca.

16. Herodoto, Historia, Libro I. Clío.

17. Pausanias, Descripción de Grecia, Libros I y II.

18. Higino, Fábulas.

19. Virgilio, Eneida.

20. Plutarco, Vidas paralelas.

21. Diodoro de Sicilia, Biblioteca histórica, Libros IV-VIII.

22. Catulo, Poemas y Elegías.

23. Séneca, Tragedias II.

24. Ovidio, Metamorfosis

25. Ovidio, Heroidas.

26. La historia completa de la genealogía cretense se encuentra en la Biblioteca histórica de Diodoro de Sicilia; ver «Antecedentes de la historia del Minotauro. Expedición de Téctamo a Creta. El rapto de Europa y la familia de Minos. Los hijos de Minos II y el asesinato de Androgeo» (Biblioteca histórica, p. 150). 
de Helios, se enamorara del toro ${ }^{27}$. Para lograr su propósito, la reina pidió el apoyo de Dédalo. El ingenioso inventor cumplió con el pedimento y resultado de esto nació el Minotauro. Minos sabiendo la culpabilidad que tenía, decidió no liquidarlo, encerrándolo en el famoso laberinto, realizado también por Dédalo.

Minos y Pasifae tuvieron varios hijos: Catreo, Deucalión, Glauco, Androgeo, Acálide, Jenodice, Asterión (Minotauro), Ariadna y Fedra. Sobresale Androgeo, generador de la venganza de Minos sobre Atenas por haber muerto a su causa, y razón por la cual ésta tenía que entregar tributo de jóvenes a la ciudad de Creta ${ }^{28}$. Minos tuvo relación con Escila, princesa de Mégara e hija de Niso. La princesa se enamoró de Minos y ella prometió darle el reino a cambio de hacerla su esposa, él aceptó. Escila entonces cortó de la cabellera de su padre el cabello rojo que le sostenía la vida y le daba el poder. Minos tomó la ciudad pero despreció a la princesa, horrorizado ante el parricidio. Debemos notar el emparejamiento entre este abandono y el posterior de Teseo sobre Ariadna. En ambos casos el amor hace perder la razón a las mujeres, que se ven finalmente traicionadas ${ }^{29}$.

Según el mito, Ariadna se enamora de Teseo, dándole los medios para librarse del laberinto y vencer al Minotauro. Una vez que logró salir con bien, Ariadna huyó con él creyendo en su promesa, pero por razones desconocidas y diferentes en cada autor, Teseo la abandona en la isla de Naxos, donde la encuentra Dionisos ${ }^{30}$, quien se enamora y se casa con ella ${ }^{37}$.

\section{COMPARATIVA CON LOS AUTORES ÁUREOS}

De las versiones originales del mito es poco lo que se conserva en las comedias, parece ser que nuestros autores, al menos en estas obras usaron poca de la variedad de autores clásicos 32 ; y aunque ya lo hacía notar Menéndez y Pelayo, no suele

27. El relato completo de lo sucedido con Pasífae lo podemos ver en Higino en su breve fábula de este personaje (Fábulas, p. 130)

28. No hay una homogenización en los autores sobre la cantidad y frecuencia. Higino menciona que «cada año enviarán a siete de sus hijos como alimento del Minotauro (Fábulas, p. 131). Diodoro, a su vez, dice que «Minos les ordenó que entregaran siete muchachos y el mismo número de muchachas cada nueve años» (Biblioteca histórica, p. 153). Apolodoro, por su parte, da el número de siete, pero no la frecuencia (Biblioteca, p. 160). Plutarco mantiene el número de siete hombres y tantas mujeres, y reduce el tributo a nueve años (Vidas paralelas, p. 172).

29. Este paralelismo es anotado por Ovidio, y es seguido por Lope de Vega.

30. Narra Eratóstenes: «Se dice que es la corona de Ariadna: fue el dios Dioniso quien la instaló en el cielo. Cuando los dioses festejaban la boda de Dioniso y Ariadna en la isla de Día, la novia se coronó con ellas tras haberla recibido como regalo de las Horas y de Afrodita» (Mitología del firmamento, p. 41).

31. Diodoro de Sicilia relata lo siguiente: «apareció Dioniso y, a causa de la belleza de Ariadna, arrebató la muchacha a Teseo y la tomó por esposa legítima dado que estaba extraordinariamente enamorado de ella» (Biblioteca histórica, p. 153). Apolodoro también nos relata una historia similar: «Pero Dioniso, enamorado de Ariadna, la raptó y la llevó a Lemnos» (Biblioteca, p. 165). Por su parte Higino, sí nos habla de una traición: «pensando que si llevaba a Ariadna a su patria supondría una deshonra para él, la dejó abandonada en dicha isla mientras dormía» (Fábulas, p. 132).

32. Este fenómeno es generalizado en el Siglo de Oro; nos hace notar Frédéric Serralta que «La libertad con que se privilegiaba (o incluso se modificaba) tal cual de las características tradicionales [...] no era 
resaltarse: «En vano sería buscar en estas obras nada del espíritu de la teogonía helénica, nada del carácter que los griegos pusieron en sus divinidades» ${ }^{33}$. La referencia más obvia parece ser Ovidio, sobre todo por el halo trágico y sentimental. En las Metamorfosis, Ovidio inicia su libro VIII dedicado al mito cretense con el episodio del sitio de Mégara; narra el poeta romano la transformación de Escila a causa del enamoramiento, la historia se nos da a conocer bajo la perspectiva de la princesa enamorada, falta de razón ante los efectos de Eros. Así como otras mujeres mitológicas se verán abandonas después de una traición cometida en favor del amor ${ }^{34}$.

Apolodoro nos narra solo los hechos generales, no da ningún detalle. Parece ser que los siguientes mitógrafos siguen sus pasos, con una diferencia en el caso de Higino en sus Fábulas, donde sí nos da la versión del abandono a Ariadna, conservando el resto prácticamente igual. Cayo Julio Higino, era contemporáneo de Ovidio, razón por la cual se explicaría una versión parecida a la del poeta. Hesiodo y Homero tampoco parecen ser las fuentes directas de nuestros autores áureos pues los detalles dados son mínimos. En las Metamorfosis, Ovidio no hace gala del dolor de Ariadna como lo hace en las Heroidas ${ }^{35}$, donde de manera apasionada y lastimera se sorprende ante la ingratitud de su amado.

Lope inicia su Laberinto de Creta con el sitio de Mégara. Minos narra a Feniso, su capitán, lo sucedido y manifiesta su indignación ante el parricidio. Escila por su parte le pide que cumpla su trato, pero él se niega argumentando el crimen, ella se queja de la traición y maldice al rey. Como podemos ver, Lope sigue la misma dinámica de la narración de Ovidio, salvo por la intervención del capitán. Ni sor Juana ni Calderón incluyen el tema. Es destacable en este episodio el cariz político, aunque velado, que le da Lope a Minos, sirviendo de reflejo del reinado en turno. Dice Francisco Xavier Romo Ontiveros que «el mito le sirve a nuestro dramaturgo para, desde el paganismo, distanciar sus críticas al reinado de Felipe $|1| »^{36}$. Un tratamiento parecido da sor Juana en el caso del conocido discurso de Teseo a Minos antes de adentrarse al laberinto ${ }^{37}$. Parece ser que una obra cercana destinada a la nobleza da la oportunidad de una crítica velada pero directa, «lo que dicen y hacen los dioses de la fiesta se refiere, en verdad, a los datos dinásticos y políticos de su tiempo», como afirma Neumeister ${ }^{38}$.

nada nuevo en el Siglo de Oro» (2017, p. 424).

33. Menéndez y Pelayo, 1884, p. 365.

34. Esta lógica de las consecuencias del amor pasional frente al racional lo vemos en innumerables personajes mitológicos, sobre todo los femeninos, recordemos por ejemplo a Medea, Circe, Calipso y Dido, solo por mencionar algunas. Para ver su historia en general se recomienda a Graves, 1985.

35. Dice Ariadna: «Lo que lees, Teseo, te envío desde aquella ribera desde donde a tu nave sin mí las velas sacaron, en la cual mal traicionóme mi sueño y también tú» (Ovidio, Heroidas, p. 52).

36. Romo Ontiveros, 2017, p. 169.

37. Entre los autores que tratan este tema está Marcela Henríquez Aravena, quien atinadamente comenta: «La valentía e ideales de sor Juana fluyen entre las palabras de Teseo, cuestionando abiertamente la forma de llegar a los altos mandos, colocando en tela de juicio la herencia de los tronos y la forma de alcanzar el respeto de los súbditos» (2015, p. 153).

38. Neumeister, 2000, p. 109. 
En Lope, Minos recibe la trágica noticia del reciente nacimiento de Minotauro; el embajador Polineces culpa a Júpiter de ser el padre del monstruo. El rey se lamenta de la desgracia y declara que hará pagar a Atenas por ella ${ }^{39}$. Tanto en Amor es más laberinto, como en Los tres mayores prodigios, Asterión ya tiene una existencia previa, el enfrentamiento de Creta con Atenas solo es un medio de allegarse el alimento del Minotauro.

Lope presenta a Minos quejoso ante sus enemigos vencidos, pidiéndoles diez hombres cada año, número superior al dado por los clásicos grecolatinos. Los enemigos aceptan casi compareciéndose del rey. Minos en sor Juana y Calderón no es mostrado como una víctima, sino como un gobernante cruel y vengativo que no tiene miramiento de la desgracia. Un ejemplo es cuando el Rey pide hablar con Teseo: «con todo quiero esta vez, / incitado de su fama, / ver al Príncipe, y saber / de su boca sus hazañas, / Para que mejor se temple / lo ardiente de mi venganza, / viendo cuán grande es la ofrenda / que sacrifico a sus aras» ${ }^{40}$. Es interesante notar que las tres comedias iban dirigidas a la nobleza, lo que podía dar un doble mensaje. En Lope, Teseo, Albante y Fineo deciden que el procedimiento de mandar los diez hombres anuales será dejado a la suerte, en las otras comedias el procedimiento se obvia.

Las comedias entonces se vuelven hacia los triángulos amorosos, mismos que no existen en ninguna de las fuentes clásicas. Los autores áureos enriquecen con detalles lo que los clásicos solo enuncian, y eso es en sí mismo una aportación significativa ${ }^{41}$. En lo que concuerdan todas las fuentes es en el enamoramiento de Ariadna sobre Teseo, pero no de Teseo sobre Ariadna, es ella quien pierde la razón y le da los medios para salir victorioso del lance. No hay detalles, salvo en Ovidio. Es quizá por esta razón que las comedias aquí comentadas abundan sobre todo en este tema. Lo que tampoco se detalla es la forma en la cual Teseo entra al laberinto, se enfrenta al Minotauro y sale de él. Ovidio en las Metamorfosis solo plantea la situación en pocas palabras: «pero he aquí que Ariadna, la hija de Minos, le entregó un hilo que éste ató a la entrada del laberinto, saliendo felizmente después de dar muerte al Minotauro» ${ }^{42}$. Apolodoro por su parte nos dice que después de desplegar el hilo Teseo mata a puñetazos al minotauro. Diodoro, Higino y Plutarco solo destacan su triunfo, pero no explican la forma en que lo logra.

En Amor es más laberinto, en la jornada segunda a cargo de Juan de Guevara, se añade una pequeña escena donde Atún el gracioso da cuenta de la entrada de Teseo al laberinto, pero no da más detalles acerca de lo sucedido: «Salgamos a ver el día, / que hay un Laberinto grande, / en este que estoy metido; / plegue a Dios que

39. Estamos de acuerdo con Romo Ontiveros en que la venganza mueve las acciones impulsivas del rey, sus actos no se fundamentan con la razón, sino que parten de la falta de moderación de sus pasiones (ver Romo Ontiveros, 2017, pp. 164-168).

40. Sor Juana Inés de la Cruz, Obras completas, tomo IV, Comedias, sainetes y prosa, p. 221.

41. Un ejemplo es el caso de Dédalo, quien aparece en los clásicos solo como el constructor del laberinto, excepto en Ovidio, donde lo vemos generar los problemas y solucionarlos con fatales resultados. Lope y Calderón lo incluyen como el ingenioso ayudante, aunque sor Juana lo omite. Ver Ovidio, Metamorfosis, p. 152, donde anota varios pasajes del personaje.

42. Ovidio, Metamorfosis, p. 151. 
ello en bien pare» ${ }^{43}$. En la versión de Lope, Ariadna enamorada de Teseo y olvidando muy pronto a Oranteo, le da tres objetos para salir vivo: el hilo, un mazo y tres panes envenenados. En el caso de Calderón, Ariadna le pide ayuda a Dédalo, el inventor le da personalmente a Teseo un hilo, unos polvos que harán que el Minotauro pierda el conocimiento y un acero para que pueda darle muerte. Las escenas dedicadas a la aventura dentro del laberinto son más las ágiles y graciosas de la comedia, Calderón explota con detalle lo vivido por los personajes dentro del laberinto ${ }^{44}$. Este juego en escena nos deja ver el espectáculo cortesano que debió tener los Los tres mayores prodigios.

Una vez fuera del laberinto, los mitógrafos son parcos al referirse a los hechos, Ovidio solo menciona la crueldad e ingratitud de Teseo al dejar abandonada a Ariadna. Tanto Apolodoro como Diodoro, hacen referencia a la entrega del hilo, la huida y el rapto de Ariadna por parte de Dionisos. En esta versión no hay un abandono, Teseo sufre por la pérdida de su amada, razón por la cual olvida cambiar las velas de negras a blancas a su regreso a Atenas, cuya consecuencia será el suicidio de Egeo, su padre.

Es hasta entrado el siglo I, con influencia de Ovidio, que los autores cambian la versión del rapto de Ariadna, al abandono perpetrado por Teseo ${ }^{45}$. Plutarco sigue con la versión de Ovidio acerca del abandono, sin embargo añade comentarios desde un punto de vista histórico de los mitos bastante interesantes. Cita a tres presocráticos: Ferécides, Filócoro y Clidemo, de quienes no tenemos sus obras, pero a partir de las cuales Plutarco considera que el mito del Minotauro está basado en hechos mucho más sencillos y humanos. Según Filócoro, Taurus no era un monstruo, sino un general de Minos, que lo traiciona con su esposa. El rey aprovecha unos certámenes de lucha para enfrentar a Teseo y a Taurus, batalla en la cual sale perdedor el general Minoico a complacencia de la venganza de Minos. Es también en este certamen que Ariadna se enamora de Teseo. Sobre la huida y el abandono no hay nada seguro según Plutarco ${ }^{46}$. El mito termina en la isla de Naxos, no así las comedias, que muestran un después muy profuso a partir de la liberación de Teseo. Sin embargo, estos acontecimientos poco o nada tienen que ver con el mito. Las historias se centran en los equívocos tradicionales de la comedia nueva,

43. Dice Atún en palabras de Juan de Guevara: «Salgamos a ver el día, / que hay un Laberinto grande, / en este que estoy metido; / plegue a Dios que ello en bien pare» (sor Juana Inés de la Cruz, Obras completas, tomo IV, Comedias, sainetes y prosa, p. 258)

44. El motivo del laberinto es común en Calderón: «Uno de los espacios privilegiados del mal en los autos sacramentales de Calderón es la presencia del laberinto como símbolo teratológico, cuya construcción deriva de diversas fuentes mitológicas que el dramaturgo emplea a su libre albedrío» (Escudero y Oteiza, 2013, p. 127).

45. Un tema desarrollado en estas tres comedias es el engaño y como consecuencia de él, el abandono. Son Teseo y Minos los principales perpetradores del engaño, al fingir apego y traicionar el amor de Escila y Ariadna. Este juego de mentiras puede ser reflejo de lo que se llegaba a vivir en la corte, recordemos que al ser obras hechas para este ámbito, también se reflejaban sus costumbres. Para este tema ver Martínez Berbel, 2015.

46. Plutarco, Vidas paralelas, p. 176. 
en los enamoramientos múltiples y las quejas amorosas. Inicia así mismo el espectáculo cortés en toda su extensión.

Aunque sin duda el autor más usado por áureos y novohispanos es Ovidio, la fuerte más directa no fueron los clásicos, sino los comentarios a estos, como es el caso de Jorge Bustamante con Las transformaciones de Ovidio en lengua española de 159547, quien sintetiza los textos del romano, pero con serias modificaciones. Es obvio, tomando los cambios por el argumento, que Lope se basa en este autor para su comedia. Bustamante plantea una participación activa de Fedra y por primera vez se refiere a un triángulo amoroso entre ella, Ariadna y Teseo. Así también es fácil considerar que Calderón se haya basado, no solo en Bustamante, sino en el mismo Lope para la recreación de su obra ${ }^{48}$.

En el caso de sor Juana, dudamos de la utilización de Jorge Bustamante, propondríamos que tomó en cuenta para su comedia, las anteriores de Lope y Calderón, más Calderón que Lope, si consideramos los triángulos amorosos que propone y la lejanía argumental de los clásicos. Un detalle interesante son las armas dadas a Teseo: tres panes o bultos con los cuales se envenenará, un metal con el cual golpear al monstruo y tres, el famoso hilo para salir del laberinto. El primero en incluirlos no es Ovidio, sino Bustamante, elementos que usa Lope y después Calderón, en el caso de sor Juana solo añade el uso del hilo.

El triángulo amoroso, desarrollado tan profusamente por los tres dramaturgos, es incluido por Bustamante en los mismos términos que es tratado en las comedias, veamos el fragmento: «Después salió por el hilo, por donde entró habiendo aguardado salir de noche. $Y$ en este tiempo secretamente se fue al aposento de las damas, a quien llevó consigo. [...] enamorándose de Fedra desamparó allí a Ariadna, en aquella isla solitaria como hombre cruel y desagradecido» ${ }^{49}$. El enamoramiento de Teseo y Fedra no existe en el mito clásico, aun cuando posteriormente hayan contraído matrimonio, al ser dada por sus hermanos ${ }^{50}$. El texto de Jorge Bustamante deja allí la historia, abriendo un espacio para la recreación de una intriga palaciega.

El amor parece ser el punto de quiebre en las diferentes versiones del mito cretense, es decir, Escila, Ariadna y Fedra son personajes trágicos, sus enamoramientos no son en absoluto correspondidos, sus amados aceptan sus dádivas, pero traicionan esos favores huyendo y mostrándose con ingratitud. La venganza y el

47. La información está tomada de la versión digital de la Biblioteca Virtual Cervantes; dicha reproducción pertenece al ejemplar original de la Biblioteca de la Universidad Complutense de Madrid.

48. Sabemos que sin duda Calderón se basa en la obra de Lope para la escritura de sus comedias, "reescribiendo" a partir del maestro. No solo hay comedias parecidas en su argumento, sino también versos familiares o incluso iguales. Sabemos también que, aunque no había una enemistad declarada literariamente entre Lope y Calderón, «siempre se ha dado por supuesta una relación de animadversión entre ellos» dice Germán Vega, sobre todo porque «la lógica nos dice que su molestia debería ser directamente proporcional a los éxitos del competidor: pero en ningún momento nombra abiertamente a Calderón» (Vega García-Luengos, 2010, p. 376). Lope debió de sentirse desplazado por los más jóvenes. 49. Bustamante, Las transfiguraciones de Ovidio en lengua española, p. 122.

50. Esta historia, la podemos verificar no solo en los mitógrafos mencionados, sino también en la tragedia Fedra de Séneca y en Hipólito de Eurípides. 
amor generan y nutren los argumentos de las comedias, son los personajes femeninos los que pierden la razón a causa de su enamoramiento, más en sor Juana y en Lope, en quien, según Óscar García: «Todos estos personajes están marcados por una enajenación transitoria debida a la pérdida de los amantes, lo que les lleva a actuar sin control y a ser temidos por los que les rodean» ${ }^{51}$. Es el momento del embeleso amoroso de ellas, el que desarrolla la trama y la complica.

En las tres comedias, Ariadna y Fedra sufren severas modificaciones, no tienen un destino funesto, sino aparentemente feliz ${ }^{52}$. Los protagonistas se convierten en personajes de comedia palatina ${ }^{53}$, solo la Ariadna de Lope sufre el desengaño, pero este no es tal como para tornarse tragedia, de hecho, la Ariadna de la tercera jornada es un personaje pastoril que conserva pocos de los elementos esenciales de la primera y más aún del personaje clásico. Después de que Teseo se fuga con Fedra dejándola en la isla de Lesbos, se disfraza de pastor, teniendo bajo este disfraz varios enredos amorosos, ya que suscita que una pastora llamada Diana se enamore de ella vestida de hombre. Después de varios enredos finalmente Oranteo se casa con Ariadna y Teseo se queda con Fedra, quien ya parece no oponerse a ese destino y ambos haber olvidado lo sucedido, todos se quedan en pareja y en paz las dos ciudades, estos finales separan definitivamente a las comedias del mito.

Las mujeres de los tres dramaturgos son las generadoras de las problemáticas, quienes tratan de resolverlos y sufren sus consecuencias. La participación activa de las mujeres se nota más en Calderón que en sor Juana. Ariadna y Fedra en Calderón son el eje de toda la comedia, su tinte cortés y teatral tiende mucho más a lo cómico, ellas no sufren, actúan para lograr sus objetivos: piensan, planean y resuelven lo que se proponen. Sor Juana, por su parte despliega en los diálogos su estética amorosa tendiente a lo intrincado y racional ${ }^{54}$, pues toma el laberinto como metáfora del amor, oscuro, complicado e incluso peligroso. Como dice García Valdés, «los argumentos le sirven a sor Juana para hablar de amor, de las varias clases de amor que con tanto talento trató en su lírica» ${ }^{55}$. La no correspondencia subyace en las mujeres clásicas y áureas, se aferran al tomento de los sentimientos, aun cuando saben que su apego no tendrá resultados favorables.

Estas características amatorias las podemos observar en Lope y sor Juana, más no así en Calderón quien nos presenta desde la primera escena una situación peculiar y cortés, donde las damas: Fedra, Ariadna y Flora, sirvienta de estas, huyen en el bosque del ataque de un oso. Teseo y su criado Pantuflo pasaban por allí casualmente, por lo cual Teseo logra matar al oso y salvar a las damas. Lidoro,

51. García Fernández, 2007, p. 192.

52. Para ver a detalle las clasificaciones temáticas respecto de la comedia nueva remito a Arellano, 2012. 53. Dice Ignacio Arellano: «lúdicas con tramas de enredo, rasgo que comparten con las de capa y espada [...] la acción se sitúa en la lejanía espacial y/o temporal» (2012, p. 139). Ver también el interesante estudio de García Valdés, 2011.

54. Aunque este concepto se aduce en el total de la comedia, podemos dar el siguiente ejemplo: «Ariadna.- ¡Qué es aquesto, Cielo injusto? / ¡Qué es lo que pasa por mí, / que lo acierto a padecer / y no lo sé definir?» (sor Juana Inés de la Cruz, Obras completas, tomo IV, Comedias, sainetes y prosa, p. 244). 55. García Valdés, 2011, p. 84. 
personaje que también aparece en Amor es más laberinto enamorado de Fedra, aprehende a Teseo y a su criado, tratando de recuperar el número de hombres que lleva como tributo a Creta. El hecho de que Teseo sea llevado al Minotauro por equivocación le quita la heroicidad del sacrificio por su pueblo. El Teseo de sor Juana diferente al de Calderón, se muestra heroico e incluso en su conocido discurso a Minos da muestras morales de lo que debe ser un buen gobernante.

En Calderón no hay pasiones violentas, tanto Ariadna como Fedra le deben la vida a Teseo, salvársela a él es un acto impulsado por el amor, la justicia y el agradecimiento. De hecho, ellas mismas dudan de sus sentimientos, se confunden entre el amor y la gratitud. Aunque las dos aman a Teseo es Ariadna quien se pone en acción; Fedra se lamenta, pero no se atreve a tratar de cambiar el destino.

Calderón es el único que hace vívida la escena dentro del laberinto, dándole un cariz más cómico a la obra. La valentía e intrepidez que demuestra Teseo se opone a los graciosos temores de Pantuflo, consecuencia de lo cual pierde el hilo mandado por Ariadna. Personaje activo y de una gran plasticidad que hace contrapeso de Teseo. No sirve de su conciencia, como sucede con el gracioso de Lope. Calderón sigue con la versión propuesta por Jorge Bustamante y después por Lope, acerca de las armas de Teseo. Dédalo entrega la ayuda, mencionando que es de parte de una de las damas, Teseo y Pantuflo se tornan de esta manera en los personajes a salvar cambiando el rol con las damas.

Pese a que Lope modifica el mito sus personajes conservan más elementos clásicos, es decir, las mujeres siguen siendo víctimas de su enamoramiento, entran en acción para lograr sus objetivos amorosos sin buenos resultados. En esta comedia es el ingenio de Ariadna lo que salvará al héroe. Ella es la enamorada, Fedra solo acompaña a su hermana en sus aventuras, es el apoyo moral, pero en ningún momento se muestra enamorada de Teseo y dispuesta a competir por él. A Ariadna la impulsa el amor, ama, olvida, se arriesga, pierde la razón para verse despojada después; Fedra es pasiva, apenas se defiende, sigue su destino sin oponer demasiada resistencia. Ariadna podría ser la representación de la guerrera, Fedra del hogar, la comprensión, la paciencia. Teseo sigue siendo un héroe, sin embargo osado y mal agradecido. Esta actitud del Teseo ovidiano se separa del heroico, anterior al poeta romano, quien se ve inmerso en la tristeza al verse despojado de su amada ${ }^{56}$.

En la versión de Lope, Teseo se da cuenta que los vientos no han sido favorables para la navegación, lo que considera consecuencia por llevar dos mujeres en plagio, decide entonces dejar a una de las dos. Fineo su criado, que funge también como la conciencia moral desaprueba la intensión de Teseo de dejar sola a Fedra en la isla de Lesbos, creyendo que seguía en palabra de casamiento con Ariadna. Teseo lo desmiente diciendo que no pretende llevarse a Ariadna sino a Fedra de quien se ha enamorado durante el viaje. Fineo se molesta pues considera indigno abandonar a una mujer que le salvó la vida, le dice entonces a su amo: «dejar a Ariadna, / esa es

56. El episodio es narrado por Apolodoro: «Teseo, entristecido por Ariadna, olvidó desplegar las velas blancas al acercarse a la costa; Egeo, al ver desde la Acrópolis la nave con velas negras, creyendo que Teseo había muerto, se precipitó y murió» (Biblioteca, p. 165). 
bajeza, señor, / indigna de tu valor / y una ingratitud villana» ${ }^{57}$. Fineo decide dejar a su amo, pues este amenaza con matarlo. Teseo finalmente aprovecha que Ariadna duerme para llevarse a Fedra por la fuerza.

Cuando Ariadna despierta y se da cuenta de la realidad, el personaje vuelve a ser trágico, burlada y sola, encuentra refugio en la ayuda que le ofrece Fineo. El soliloquio proferido ante la traición de Teseo se asemeja a los lamentos de la Ariadna Ovidiana de las Heroidas cuando se percata de la ausencia: «me levanto aterrada, y mis miembros del viudo lecho se precipitan. Al punto resonaron mis pechos al golpearlos mis palmas, y, revuelto como era del sueño, arranqué mi pelo» ${ }^{58}$. Sin embargo, el dolor del abandono no es permanente ni atroz, las comedias se separan así de lo mitológico.

\section{CONCLUSIONES}

Dentro del universo de las comedias áureas encontramos el uso de la mitología grecorromana como argumento para obras pensadas y representadas para la corte. Los ejemplos usados en este trabajo toman como eje el mito en torno del Minotauro, aunque con importantes modificaciones. Se revisaron comparativamente: El laberinto de Creta de Lope, Los tres mayores prodigios, de Calderón y Amor es más laberinto de sor Juana. Se verificó que las fuentes usadas por los dramaturgos no son los clásicos grecolatinos, aunque tienen mayor cercanía a las Metamorfosis de Ovidio, sino a las interpretaciones de los mitos surgidas en el Siglo de Oro, como es el caso de Jorge Bustamante.

Se observó cómo la influencia de Lope es determinante en los otros dos autores, pues sus obras tienen ecos de este. Los notorios cambios en el mito obedecen a las características comunes de las comedias mitológicas, que por lo general se representaban ante un público selecto y haciendo uso de técnicas dramáticas y de representación más elaboradas en comparación con las comedias de corral. Los cambios en el argumento se dan sobre todo hacia el final de las comedias, donde vemos una participación activa de los personajes femeninos y una focalización en los enredos amorosos. Sin duda estas tres obras nos muestran la importancia de tuvieron y siguen teniendo las comedias mitológicas para el conocimiento del siglo XVII.

\section{BiBLIOgRAFÍA}

Apolodoro, Biblioteca, Madrid, Gredos, 2002.

Arellano, Ignacio, «La comedia mitológica de Calderón», en Calderón de la Barca, El monstruo de los jardines, ed. Juan Mayorga, Madrid, RESAD, 2001, pp. 9-28.

Arellano, Ignacio, Historia del teatro español del siglo XVII, Madrid, Cátedra, 2012.

57. Lope de Vega, El laberinto de Creta, p. 146. Tomado de la edición digital de la Biblioteca Virtual Miguel de Cervantes.

58. Ovidio, Heroidas, p. 52 
Ávila, Alán, «Hacia una introducción a la comedia mitológica del Siglo de Oro», Revista Destiempos, 57, 2016, pp. 24-33.

Ávila, Alán, «Notas sobre la comedia mitológica de Lope de Vega», Revista Destiempos, 57, 2017, pp. 7-23.

Bustamante, Jorge, Las transfiguraciones de Ovidio en lengua española; repartidas en quince libros, con las alegorías al fin de ellos, y sus figuras para provecho de los artífices, traducción y comentarios Jorge Bustamante, España, Casa de Pedro Bellero, 1595.

Calderón de la Barca, Pedro, Los tres mayores prodigios, Madrid, por Francisco Sanz, 1683.

Catulo y Tibulo, Poemas y Elegías, Madrid, Gredos, 1993.

Diodoro de Sicilia, Biblioteca histórica, Libros IV-VIII, Madrid, Gredos, 2004.

Eratóstones, Mitología del firmamento (Catasterismos), Madrid, Alianza Editorial, 1999.

Escudero Baztán, Juan Manuel, y Oteiza, Blanca, «El laberinto, motivo sacramental en Tirso y Calderón», Anuario Calderoniano, vol. extra 1, 2013, pp. 127-145.

García Fernández, Óscar, «La locura de amor en el teatro mitológico de Lope de Vega», en Locos, figurones y quijotes en el teatro de los Siglos de Oro, Almagro, Ediciones de la Universidad de Castilla-La Mancha, 2007, pp. 183-194.

García Valdés, Celsa Carmen, «Las comedias de Sor Juana Inés de la Cruz y el Arte nuevo de Lope de Vega», Rilce, 27.1, 2011, pp. 77-102.

Graves, Robert, Los mitos griegos, Madrid, Alianza, 1985.

Henríquez Aravena, Marcela, «Reescritura del mito de Teseo en Amor es más laberinto de Sor Juana Inés de la Cruz», Revista Inclusiones, 2.2, 2015, pp. 142-156.

Herodoto, Historia, Libro I. Clío, Madrid, Gredos, 1992.

Higino, Fábulas, Madrid, Gredos, 2009.

Juana Inés de la Cruz, sor, Obras completas, tomo IV, Comedias, sainetes y prosa, México, FCE e Instituto Mexiquense de Cultura, 1994.

Martínez Berbel, Juan Antonio, «Una aproximación al tema del engaño en algunas comedias de Lope de Vega», Hipogrifo. Revista de literatura y cultura del Siglo de Oro, 3.1, 2015, pp. 35-53.

Martínez García, Óscar, «"Fortuna" del mito de Teseo: del Renacimiento hasta el siglo XIX», Estudios Clásicos, 115, 1999, pp. 51-71.

Menéndez y Pelayo, Marcelino, Calderón y su teatro, Madrid, Imprenta de A. Pérez Dubrull, 1884.

Menéndez y Pelayo, Marcelino, Estudios sobre el teatro de Lope de Vega, tomo II, Madrid, Librería General de Victoriano Suárez, 1921. 
Neumeister, Sebastián, Mito clásico y ostentación. Los dramas mitológicos de Calderón, Kassel, Reichenberger, 2000.

Ovidio Nasón, Publio, Heroidas, introducción y notas Tarsicio Herrera Zapién, México, UNAM, 1979.

Ovidio Nasón, Publio, Las metamorfosis, México, Espasa-Calpe Mexicana, 1995.

Paladino, Mónica, «Teseo y las princesas de Creta en Amor es más laberinto», en De ayer y hoy. Influencias clásicas en la literatura, coord. Aurora López, Andrés Pociña y Maria de Fátima Silva, Coimbra, Centro de Estudos Clássicos e Humanísticos da Universidade de Coimbra, 2018.

Pausanias, Descripción de Grecia, Libros I y II, Madrid, Gredos, 1994.

Plutarco, Vidas paralelas, I, Madrid, Gredos, 1985.

Romo Ontiveros, Francisco Xavier, «El ejercicio del poder injusto: El laberinto de Creta de Lope», en 25 años de la AITENSO. Homenaje a Francisco Ruiz Ramón, ed. Ysla Campbell, Ciudad Juárez, Universidad Autónoma de Ciudad Juárez, 2017, pp. 159-172.

Séneca, Tragedias II, Madrid, Gredos, 1980.

Serralta, Frédéric, «El mito de Troya en la escritura teatral de Lope», Hipogrifo. Revista de literatura y cultura del Siglo de Oro, 5.1, 2017, pp. 421-431.

Vega, Lope de, El laberinto de Creta, Madrid, por la viuda de Alonso Martín, a costa de Alonso Pérez, 1621. Alicante, Biblioteca Virtual Miguel de Cervantes, 1999.

Vega García-Luengos, Germán, «Calderón, reescritor de Lope», Anuario Calderoniano, 3, 2010, pp. 371-403.

Villarejo, Óscar, «Revisión de las listas de El peregrino de Lope de Vega», Revista de Filología Española, XLVI, 3-4, 1963, pp. 343-399.

Virgilio, Eneida, introd. Vicente Cristóbal, Madrid, Gredos, 1992. 